\title{
El gesto instrumental y la voz cantada en la significación musical
}

\section{The Instrumental Gesture and the Singing Voice as part of the Musical Significance}

\author{
por \\ Jorge Martínez Ulloa \\ Facultad de Artes, Universidad de Chile, Chile \\ jorgmart@uchile.cl
}

\begin{abstract}
El escrito está articulado en tres partes. En la primera se presenta una breve reflexión sobre las modalidades en que el cuerpo del músico actúa y condiciona el gesto sonoro, tanto en el cantante como en el instrumentista. En la segunda se hace uso de la filosofía de Merleau-Ponty para describir la relación cuerpo-mundo físico y sus implicancias en el conocer. Finalmente, en la tercera parte, se analizan las consecuencias de dicha filosofía para una mejor comprensión de lo musical como fruto de cuerpos y dirigido a cuerpos, concluyendo que lo esencial de la música se juega en una fase prediscursiva, como indicalidad del emocionar corpóreo: un ex-cribir el cuerpo más allá de éste.
\end{abstract}

Palabras clave: cantante, gesto instrumental, objeto sonoro, cuerpo sonoro, fenomenología de la música, prediscursiva, ex-critura, cuerpo y música, sensibilidad.

This article is divided into three parts. In the first part, a brief reflection is presented about the ways in which the musician body acts and at the same time conditions the sound gesture, both among singers and instrument players. In the second part, the author resorts to the philosophical thought of Merleau-Ponty in order to describe the relationship between body and physical world and the ways this relationship influences the process of knowing. Finally, in the third part, the consequences of this philosophy are analyzed in terms of its contribution to a better understanding of the musical process as something produced by bodies which in turn address itself to other bodies. The conclusion states that the essence of music unfolds itself not in the discourse itself but in a moment antedating the discourse, or a prediscoursive moment, as an indication of the bodily emotion, or a way of projecting the body, beyond the body itself.

Keywords singer, instrumental gesture, sound object, sound body, phenomenology of music, pre-discoursive moment, body projection, body and music, sensitivity.

\section{$\mathrm{UNO}$}

En el español antiguo la palabra "canto" significaba indistintamente "piedra" o "voz musical", como es el caso, a modo de ejemplo, en la denominación Puente de Cal y Canto, cuyo significado remitía a la piedra. Esta connotación lítica acompañó desde siempre a la voz musical, por lo menos en las áreas de lengua hispana. Sería interesante efectuar un estudio comparado translingüístico y etimológico del término, pero excede los límites de este trabajo. La voz musical era considera- 
da una de las expresiones más altas de la significación simbólica. En la iconografía medieval la voz aparece como un fluido que se eleva desde la boca del cantante hacia el cielo.

Siempre la voz estuvo ligada a simbologías de trascendencia y elevación física. Por las mismas razones, conjuntamente con los aerófonos (flautas y trompetas), constituían la llamada música mundana que, con las categorías de humana e instrumentalis, conformaban la trilogía clasificatoria del musicum. El canto, por lo tanto, va a significar no sólo la voz sonora, sino que, además, la expresión más elevada del sacrificio, pues su existencia acústica se debe al gasto del aliento del cantante, aliento que también es el soplo vital de todo ser vivo. Cantar es sacrificar parte de la propia vida, en la medida en que ésta es expresión del aliento o soplo vital. De allí que el canto va a ser el vehículo privilegiado de la simbólica mágica y religiosa. Si, para usar los conceptos de magia homeopática y simpática de Frazer ${ }^{1}$, el mago o chamán desea actuar sobre las cosas o fuerzas naturales, esta influencia se debe hacer con fuerzas y elementos análogos a la constitución del mundo. Para influir sobre la vida se debe ejercitar un mecanismo vital: el semen o el aliento vital. De allí, a su uso tradicional en prácticas litúrgicas y religiosas, el paso era breve y bastante obvio. Cabe señalar que hasta hoy se habla de "cantar misa" para una práctica litúrgica que, desde el Concilio Vaticano II, es esencialmente "hablada" y no "cantada". Esta referencia a la potencia mística de la voz es posible encontrarla en muchas prácticas litúrgicas y religiosas alrededor del mundo y de la historia, desde las magias chamánicas hasta los elaborados ritos orientales.

En la voz reside la potencia espiritual y de allí que la palabra encantamiento va a denotar la petrificación ritual. Encantar a alguien es transformarlo en piedra. Para ello el encantador debe sacrificar su soplido o aliento vital para "congelar" el aliento vital de lo encantado, en una forma de abducción de la vida, en el supuesto que la vida habita en forma de fluido o aliento un cuerpo material que le es sustancialmente extraño. Este extraer vida puede ser también invertido: Dios insufla vida en el cuerpo de Adán y Eva a través de su soplido. En las fábulas es común encontrar a doncellas encantadas que vuelven a la vida gracias a un ósculo de un joven mancebo. En este caso el beso representa una forma sin mediación de transmisión del aliento vital, metaforizado en otros relatos y experiencias por la voz cantada. Encantar es pues "transformar en piedra", extraer toda posibilidad vital para mutar al ente viviente, objeto de esta acción, en ente inanimado, cosa muerta, carne y sustancia inorgánica.

Esta petrificación puede actuar como congelamiento del tiempo, dimensión por excelencia de lo vital, como en el caso ya citado de damiselas y princesas de las fábulas, encantadas en un estado de vida suspendida. Es curioso que sea el mismo espíritu o aliento vital, por su naturaleza atemporal y eterna, el que haría vivir al cuerpo esta posibilidad cíclica de la respiración, célula originaria del tiempo de vida.

Cada respiración nos acerca a nuestra muerte, es un gasto que no puede ser reemplazado y, análogamente, consumir este aliento en la voz cantada, entrega y

\footnotetext{
${ }^{1}$ Frazer 1973: 23 y sgts.
} 
concede la propia vida a quienes escuchan, "petrificados" o "encantados", y asumen estáticamente la contemplación del sacrificio del cantante. Quizás es la misma razón por la cual se les exige a los cantantes una verosimilitud respecto a la expresión del propio espíritu en el canto, que no se les exige a los actores. En efecto, una de las condiciones de la legitimación del cantante radica justamente en esta posibilidad de expresar verídicamente su propia emocionalidad al cantar. Es normal que nadie pretenda del actor la misma veracidad: se supone que el actor interpreta personajes, no su propia emocionalidad. La sospecha en los auditores de que un cantante de moda, por ejemplo, represente sólo un personaje y no la propia vitalidad en su canto, su propia persona, es descalificadora de la experiencia y validez del canto. "Para cantar Verdi es necesario sentirlo". Esta frase, común en juicios de melómanos, es extensible a otros géneros musicales, con igual eficiencia. Al cantante le es exigida una veracidad en la expresión del propio sentimiento que no le es exigida al actor $u$ a otros profesionales de las artes de la escena.

Las referencias a esta relación: vida-aliento vital-congelamiento-encantamiento, son demasiado numerosas en la literatura, la filosofía y la estética como para proseguir por esta vía con otros ejemplos. Lo que ahora nos interesa es hacer notar esta característica para relacionar la voz humana con la otra forma de producción corpórea de sonido, el gesto instrumental.

Esta capacidad del canto de "encantar" y de ser expresión verídica del propio sentimiento ponen al cuerpo, al "cordero sacrificado", al centro de este cantamiento (en/cantamiento), como una forma de petrificar y cristalizar, congelar la vida de ese mismo cuerpo, excorporarla, reduciéndolo a contenedor-prisión de esa vida suspendida.

En el arte instrumental sucede algo aparentemente análogo y, sin embargo, radicalmente diferente. En este caso, lo "encantado" no es la vitalidad del aliento, sino que la energía cinética del gesto sonoro transformado en significante de una materia diferente, la música. El instrumento musical actúa acá como mero mediador que transforma y transduce ${ }^{2}$ ese gesto en vibraciones acústicas, nuevamente transformadas a su vez en partituras, volviendo de la dimensión acústica (y temporal) a la visual, mediante la gráfica notacional. No es tampoco intrascendente el hecho de que ese mismo cuerpo instrumental sea el territorio de otro sacrificio, ya que las maderas, tripas, membranas, cañas y todos aquellos elementos que los constituyen son ellos mismos el espacio y "la voz sacrificada", los residuos de sacrificios anteriores, a través de los cuales otros cuerpos vitales resignaron su potencialidad de movimiento en el congelamiento instrumental. En la arquitectura de todo instrumento de música están los restos de otras inmolaciones y, sólo por ello, desde una conciencia mítica, pueden resonar.

El canto no se puede ver, pero el gesto instrumental sí se puede ver. Efectivamente, este gesto constituye una forma de existencia del cuerpo del músico. El cuerpo es gesto, se expande y explaya a través de su espacio y tiempo específicos ${ }^{3}$. Pero, ¿cómo se relaciona ese gesto-cuerpo con la mente y la conciencia del músico?

\footnotetext{
${ }^{2}$ Término físico para expresar el cambio de una forma de energía en otra.

${ }^{3}$ Hatten 2004:35.
} 
La propia experiencia de muchos músicos nos cuenta de sus largos procesos de aprendizaje, en los que tratan de distanciar la propia conciencia de cada gesto, hasta hacerlos casi automáticos: "Es el cuerpo quien piensa cuando toco". "A mis alumnos les enseño a pensar con los dedos". "En la medida que el cuerpo sabe tocar, la mente estará libre para dirigir el sentido de la interpretación". "Si la mente está ocupada en dirigir el gesto, cada pequeño gesto, la interpretación será mecánica y dificultosa, lenta y pesada". "Se debe dejar que la intuición guíe el gesto instrumental”. Todos estos comentarios, comunes a músicos y profesores de instrumentos, remiten a esta posibilidad del pensar corpóreo.

En este caso, es evidente que el instrumentista, al revés del cantante, desplaza su atención lo más lejanamente posible de su gesto, para hacer que "su cuerpo piense por él". El cantante no tiene instrumento definido, él debe construirlo cada vez, sobre su propio cuerpo. ¿Cómo construye ese instrumento virtual? Lo hace a través de metáforas que expresan sensaciones. Es sobre la base del recuerdo de esas sensaciones que es posible impostar la voz. El instrumentista, en cambio, dispone de un manufacto ajeno, de una extensión de su propio cuerpo en un cuerpo diferente que comienza a hacer propio, a sentirlo como tal, a percibir a través de él, gracias al ejercicio constante.

Impostar el instrumento, es decir, encontrar una posición adecuada para que éste suene lo mejor posible, es el objetivo de todo profesor hacia su alumno. Una posición que le permita no pensar, sino que hacer que su cuerpo (comprendido su instrumento) piense en vez de él. Gregory Bateson se preguntaba: ¿Adónde termina un ciego: en la punta del bastón que golpea el pavimento, en la mano que empuña ese bastón, en el eco del golpe del bastón sobre los muros? ${ }^{4}$. De igual modo cabría preguntarse: ¿Adónde comienza (o termina) el intérprete cuando está tocando? ¿Cuáles son los límites corporales de su sentir como instrumentista? ¿Qué puede ser entonces ex-cribir un cuerpo? ¿Cómo compendiar todos esos gestos instrumentales que conforman sonidos?

En el sonido, en las series de sonidos, la sensación acústica proviene de una multitud de gestos, de una serie de estados del propio cuerpo, cristalizados y amplificados por los traductores (instrumentos de música) y dirigidos por la pura sensación. Entonces, es posible un modo de ex-cribir el cuerpo, en la música, en la medida que ésta está constituida por todos esos estados del cuerpo que son las gesticulaciones instrumentales y sus derivados: los gestos sonoros. Asimismo, trataremos de demostrar que es gracias a esta posibilidad que la música puede significar lo humano y que, de todas las formas artísticas, la música, por la misma razón, es quizás la más directamente ligada al emocionar.

El caso del gesto instrumental es diferente al de la voz. En el canto, la música y el sonido son creados mediante un instrumento virtual, que se conforma en la mente del cantante y que éste manipula y modifica según estados y procesos que tienen su origen en la conciencia. La voz del cantante, como corporalidad, no está siempre presente, sino que es una puesta en acto de posibilidades. El cuerpo

${ }^{4}$ Bateson 1984: 23-25. 
asume, en su calidad de instrumento musical, una forma que proviene de una sensibilidad evocada.

En el gesto instrumental las cosas operan de manera diferente. Primero, el cuerpo en su mera realidad física, como el espacio de una sensibilidad presente, construye y constituye el lugar de una experiencia sonora, a través de la mediación de un objeto, instrumento musical. Este objeto, en la práctica del músico, se hace cuerpo, constituyendo una extensión del propio cuerpo y campo sensible. Por lo tanto, es posible afirmar que siempre, en cada movimiento y estado del cuerpo físico, existe una posibilidad de gesto instrumental-musical.

En teoría, el repertorio de los gestos instrumentales pertinentes puede ser limitado y puede conformar un lenguaje, con sus unidades mínimas distintivas y sus niveles de articulación. En la práctica, las modulaciones que el propio cuerpo imprime a esos gestos son virtualmente infinitas. No hay dos intérpretes que repitan sus gestos en forma similar (pese a las ideologías de las escuelas y de los maestros), ya que estos dependen, en larga medida, de las posibilidades estructurales de cada cuerpo.

Finalmente, el canto se ejerce normalmente sobre un texto lírico, sobre palabras y conceptos que cargan cada sonido de una particular semanticidad y que el gesto canoro debería retomar. Lo que en el gesto instrumental es directamente cuerpo, en la voz cantada es la predicación de una enunciación metafórica que tiene lugar en el texto lírico-semántico cantado y en la imagen que de eso tiene el cantante. Por ello, la conformación de ese instrumento virtual que es el canto, es la enunciación corpórea de una metáfora abstracta. Es curioso comprobar cómo, en la experiencia del auditor, se puede tener justamente la percepción contraria, asumiendo el canto como mucho más corpóreo que el gesto. Podríamos hipotizar entonces que el movimiento que relaciona estas dos fuentes sonoras es inverso, que el canto se mueve desde una metáfora mental y semántica hacia el cuerpo y que el gesto instrumental procede en sentido contrario, desde el cuerpo hacia la conciencia.

En el canto, el cuerpo del cantante, tracto fonatorio y sus resonantes es habitado por el soplo vital, por la palabra (casi podríamos decir el Verbo, para usar la conocida metáfora bíblica) que le da plena significación y el cuerpo, la voz, es el significante de ese sentido. Pero como significante que es constituido desde la evocación de esa metáfora que entiende significar. Podríamos así recordar la locución latina: Hoc est enim corpus meum (He acá mi cuerpo). Obviamente la cuestión es mucho más compleja y cualquier cantante así lo sabe, pero lo que interesa aquí es comparar cuánto y cómo el signo de base lingüística permite explicar el canto.

En el gesto instrumental casi no hay texto ni palabras. El ademán se explica y se escribe, se traduce a sí mismo y se condensa en una célula sonora, en un gesto sonoro. ¿Es posible pensar, entonces, que el gesto instrumental escribe al cuerpo de manera diferente de cómo lo escribe la voz? Sí y no, ya que la mera virtualidad corpórea del instrumento vocal y la total otredad del instrumento físico, complican aún más la cuestión: el instrumento musical dispone de un espacio y de un límite preciso, es una cosa y, como tal, relativamente predefinido. En cambio, la voz humana es un fenómeno in potentia, jamás se sabe si está ahí y cómo, hasta que 
se experimenta en esa especie de milagro que es la resonancia de los tractos vocales, en el en-cantamiento que acompaña la voz musical.

\section{DOS}

Todos estos asuntos se comienzan a aclarar cuando consideramos la cuestión desde el punto de vista de la fenomenología y en particular desde la visión de MerleauPonty. El primer tema que nos proponemos afrontar es cómo la simbolización convencional depende, por así decir, de una suerte de simbolización natural, una especie de prerracionalidad, un logos ante-litteram que ordena, modela y modula los niveles de conciencia racionales y lingüísticos. La intención de Merleau-Ponty es mostrar que, si bien el simbolismo convencional no es reductible al natural, las convenciones sólo pueden aparecer como variantes o diferencias por la relación a una comunicación previa, esto es, presuponen la comunicación silenciosa de la percepción. De allí la existencia de un Logos primero, que determina una apertura a un Ser anterior al lenguaje y que se pronuncia en silencio sobre las cosas sensibles, Ser que es sensible él mismo, es decir, susceptible de ser sensibilizado por su mundo. Esta especie de unidad originaria determina una referencia y todo tipo de equivalencias entre los sistemas simbólicos superiores. Por esta razón, el método sobre el que se lleva a cabo la recuperación del logos estético debe tomar como ejemplo el modelo de la percepción. Es en el Sentir que se construyen las bases de ese "estar en el mundo" del que nos habla la filosofía y, obviamente, del que nos hablará también la música.

Como señaló Romero: "En el silencio de la conciencia originaria, se ve aparecer no solamente lo que quieren decir las palabras, sino más aún, lo que quieren decir las cosas, el núcleo de significado primario alrededor del cual se organizan los actos de denominación y de expresión" 5 .

La noción de esquema corporal como sistema de equivalencias y la reflexividad del cuerpo propio, hacen posible comprender el quiasmo cuerpo-cosas que implica el desdoblamiento del cuerpo en adentro y afuera, y corre paralelo al desdoblamiento de las cosas en su adentro y su afuera. Estos dos desdoblamientos hacen posible la inserción del mundo entre las dos hojas del cuerpo y la inserción del cuerpo entre las dos hojas de cada cosa y el mundo.

El cuerpo es un sensible ejemplar que ofrece a quien lo habita la posibilidad de sentir todo lo que se le asemeja en el mundo exterior. Tomado en el tejido de las cosas lo atrae todo hacia sí, y por el mismo movimiento comunica a las cosas sobre las que se cierra "esta identidad sin superposición, esta diferencia sin contradicción, esta separación del adentro y del afuera que constituyen su secreto natal" 6 .

Por su propia ontogénesis el cuerpo nos une a las cosas, manteniendo entrelazadas las dos hojas de la que está hecho: "La masa sensible que él es y la masa de lo sensible donde él nace por segregación y a la que como vidente permanece abierto" 7 . Esta doble referencia no es un hecho casual, sino que cada referencia

\footnotetext{
${ }^{5}$ Romero: 2006.

${ }^{6}$ Merleau-Ponty 1995: 179.

${ }^{7}$ Merleau-Ponty 1995: 179.
} 
llama a la otra. El mundo visto no está en mi cuerpo ni tampoco en el mundo. Entre el cuerpo como cosa sensible y el cuerpo como sintiente hay "inserción recíproca y entrelazamiento de uno en otro" o mejor dicho, "hay dos círculos, o dos torbellinos, o dos esferas, concéntricas cuando yo vivo ingenuamente, y desde que yo me interrogo, un poco descentradas una por relación a la otra" ${ }^{8}$.

Así como lo propio, de la reflexión acerca de la experiencia perceptiva es haber descubierto nuestra pertenencia al mundo y realizar su descripción sin ningún agregado que tenga su origen en el pensamiento discursivo, de igual manera el "sentir la música", el percibir el gesto sonoro como gesto musical, parte de estas bases físicas prerracionales, que son configuradas en la percepción del gesto cinético y su transformación en gesto acústico y sonido o, si se desea, en la contemplación encantada de la voz cantante.

Es propio del espíritu el acto mediante el cual nosotros reconsideramos nuestra existencia corporal y con una acción de purga la empleamos para simbolizarla en lugar de permanecer en la experiencia. De la misma manera transformamos esa percepción acústica en "sonido", como componente de una simbolización que ya es "música" (y actividad mental), marcando un distanciamiento del acto experiencial. Esto es aún más patente en la llamada música de arte o docta cuya verdadera percepción estética aviene generalmente en el silencio de la obra, en el momento inmediatamente posterior a la última nota oída: "Es esa vida segunda, y no otra cosa, lo que hace de un producto musical una obra de arte, sustrayéndola de la lógica del consumo puro y simple" 9 .

Allí se construye, casi en una perspectiva mental, con líneas de fuga y puntos de vista, todo el entramado de las relaciones simbólicas que componen el aspecto verbal de la experiencia musical, todo aquello que puede ser relatado en palabras. Quizás radique en esa calidad la gran diferencia entre la música popular, cuyo sentir se construye en el momento mismo de su experiencia, en un universo sin palabras y mediante el cuerpo vivido como espacio referencial, y la música docta, cuyo sentir requiere ese espacio de silencio estructurador mental.

Según Merleau-Ponty, las formaciones culturales no rompen el lazo con la vida perceptiva, sino que "la continúan, la conservan y la transforman" ${ }^{\text {. La mú- }}$ sica, como agregado de sonidos/gestos sonoros, primero se vive, luego se piensa. Es desde esta percepción adonde el cuerpo asume una centralidad, no sólo como soporte físico de la experiencia, sino que como límite y espacio de transición desde el cual se relacionan un adentro y un afuera. Este adentro no puede ser considerado como el lugar del sujeto, pues este mismo sujeto habita tanto el interior como el exterior de la experiencia, así como el afuera tampoco es el simple lugar del mundo. Más bien operaría, en la concepción de Merleau-Ponty, una intencionalidad en el "estar en el mundo", que partiría del mundo mismo, modulando y modelando la experiencia del espacio-límite.

Así definidas, podemos establecer dos dimensiones de esta experiencia: un cuerpo biológico: Körper, corps, por un lado y, por el otro, un cuerpo vivido-Leih

\footnotetext{
${ }^{8}$ Merleau-Ponty 1995: 182.

${ }^{9}$ Baricco 2000:29.

${ }^{10}$ Merleau-Ponty 1957: 364-365.
} 
(Husserl), corps vecu (Merleau-Ponty). Análogamente, una corporalidad, en la que es el cuerpo físico, en tanto que producto de categorizaciones de una materialidad física, un etant deja donne, que ha sido normalmente considerado objeto de estudio de las disciplinas cognitivas y una corporeidad, esto es la forma como son moduladas y modeladas las sondas cognitivas de la corporalidad, y que ha sido objeto de estudio de la fenomenología, desde Husserl hasta Merleau-Ponty. Esta dualidad aparente del sentir entre significante y significado, reposa en la unicidad de la experiencia, pues ese "ocuparse del mundo" representa directamente "un poder estar en el mundo de una determinada forma". Así establecidos los campos, pareciera ser que el campo de una neurofenomenología, tal como puede verse definida en Cuerpo Presente y en otros trabajos de Varela ${ }^{11}$, trata de establecer puentes entre esta suerte de reduccionismo cognitivista y la explicación fenomenológica.

El cuerpo vivido es el sujeto de las acciones habituales que pueden realizarse independientemente de la razón. El cuerpo vivido no se inscribe ni en el dominio físico-objetivo de las ciencias empíricas, ni en el dominio puramente ideal de las representaciones mentales. Su modalidad de existencia es la de un objeto intencional, vivido fenoménicamente como percepción corporalizada, con preeminencia sobre la conceptualización abstracta. Es el órgano de la percepción y a la vez el objeto de la misma: sin corporeidad no hay ni percepción ni razón. El cuerpo vivido es parte tan importante de la mente y del cuerpo físico, que: "El mundo no es lo que yo pienso, sino lo que yo vivo" 12 . Corporalidad y corporeidad son dos aspectos íntimamente relacionados en nuestra realidad de seres encarnados. Entre ambas existe una circulación ${ }^{13}$ y es la llamada "enacción", superando el dualismo racionalista mente-cuerpo (Platón, Descartes, Kant). Estas posiciones estarían resueltas (Aufgehoben) en la experiencia corporalizada, prerreflexiva y ambigua del mundo vivido (Lebenswelt) en un cuerpo que funde naturaleza y cultura.

\section{TRES}

Para el caso específico de los gestos corporales de pertinencia musical/gestos sonoros, la fenomenología de Merleau-Ponty, desde la corporeidad, presenta una suerte de cuerpo vivido-sonoro. Un gesto que, antes de ser pensamiento, quantum, idea o concepto, es directamente la experiencia de capacidades sensibles, perceptivas, prerracionales y, por ende, antepredicativas y antelingüísticas. Ello determina la gran potencia emotiva de este gesticular sonoro, ya que este signo sensible acompaña estados emotivos especiales, los significa en tanto que índices (en la definición Peirciana) e iconos. En el primer caso, el signo es correlativo al fenómeno que significa, y desde la relación signo-objeto, es concomitante con lo significado: "el humo que acompaña al incendio". Para el caso específico del gesto corpóreo-sonoro, esta sonoridad de la percepción acústica radica justamente en

\footnotetext{
${ }^{11}$ Varela 1995.

${ }^{12}$ Merleau-Ponty 1957:16.

${ }^{13}$ Varela 1992: 18.
} 
esta capacidad de acompañar, como sonido, una determinada modulación del cuerpo vivido del intérprete, de su emocionar, en tanto que estado de su soma y percepción del mismo. Por esta misma razón, por esta indicalidad del gesto sonoro, antes de declararse la "música" como espacio lingüístico y cultural, este gesto sonoro está significando un determinado emocionar, en forma antepredicativa. Por ello la música antes que pensarse, se vive.

Otro aspecto importante de la significación musical, radicada en la gestualidad sonora, es la posibilidad icónica, es decir, el sonido como análogo a las derivas temporales del fenómeno acústico. En un momento posterior estas trayectorias, sucesiones, podrán ser traducidas como melodías y notaciones gráficas. Allí se puede pensar que estos iconos ex-criben la deriva de una temporalidad de los estados gestuales-corporales y sus correlatos emocionales. El tercer nivel del signo peirciano, en la relación signo-objeto, está ocupado por el llamado símbolo, es decir, un tipo convencional de signo cuya relación con lo significado es de pura convencionalidad. Finalmente, este último nivel podría ser definido como de base lingüística o, si se desea, expresable en palabras y conceptos. Los dos niveles anteriores son inexpresables en palabras. Para el primero de ellos, el índice, su experiencia debe suceder en el instante mismo del acto en que el fenómeno existe. Está directamente fundido con la experiencia del productor y de su receptor.

Se puede constatar que en la significación musical aquellos signos índices e iconos representan gran parte de la experiencia musical, seguramente la más directa y, podríamos agregar, la más resonante, en un concepto de resonancia que es definido por Nancy como lo propio de la experiencia musical de la audición: "La repetition où le son s'amplifie et se propague aussi bien que le rebroussement où il se fait écho en se faisant entendre" (La repetición donde el sonido se amplifica y se propaga, así como la vuelta sobre sus propios pasos, de la cual se hace eco al hacerse oír) y "Acces au soi: ni a un soi propre (moi), ni au soi d'un autre, mais bien à la forme ou à la structure du soi en tant que tel, c'est à dire à la forme, à la structure d'un renvoi infini puisque il renvoie à ce (lui) qui n'est rien hors du renvoi"14. (Acceso al sí: no a un sí propio [yo], ni al sí de otro, sino ya sea a la forma o a la estructura del sí en tanto que tal, es decir a la forma, a la estructura de un reenvío infinito, dado que remite a aquello [él] que no es nada fuera del reenvío). Este concepto de resonancia aparece como "verdad", como un paisaje acústico que no tiene límites, pues en el oírle, en "tender la oreja" hacia él, el paisaje acústico se dilata cada vez más en la experiencia. Todo esto mucho más allá del campo semántico de cualquier palabra, casi en la negación de la posibilidad contenedora de la palabra.

El índice en cuanto signo, debe existir en concomitancia con el acto musical, con la experiencia de ese acto. Puede ser pensado como característico del gesto instrumental, que existe en la experiencia del sonido en el momento que se produce, como un reenvío de sí, que no existe más que como posibilidad de tal reenvío. En consecuencia, la voz humana se relacionaría más con el signo en cuanto

${ }^{14}$ Nancy 2002:25. 
ícono, analogía y representación de metáforas mentales, en las cuales el cuerpo fónico del cantante se construye en la virtualidad de esa analogía, definida en el contexto del "decir" palabras, cantar semas.

Los símbolos más convencionales y fundados en la palabra representarían aspectos mucho más mediados de la significación musical, en la evocación resonante del cuerpo vivido. Sin embargo, es el índice el más potente y directo significador de la experiencia sonora, en cuanto ligado existencialmente a la experiencia y al fenómeno que significa y, a través de él, al emocionar que subtiende este ser-cuerpo-sonoro.

El índice, en cuanto existente en el fenómeno mismo, ex-cribe el cuerpo sonoro del instrumentista. En el cantante este índice es la corporeidad de una virtualidad imaginada. En ambos casos, sin embargo, puede ser asumido como signo de un gesticular acústico que es directa experiencia de un emocionar. El índice puede entonces considerarse, en cuanto actividad perceptiva más compleja, dentro de la experiencia, como un correlato sonoro/emotivo y la base de toda experiencia estética, como la percepción de esa correlación. Este emocionar no es solamente personal, sino que puede ser patrimonio de comunidades musicales enteras, en la medida que esas comunes unidades hayan experimentado fenómenos parecidos, en circunstancias compartidas, durante largos períodos de tiempo. Por ello, la música, como sistema cultural, puede entenderse conformada, tanto por productos (obras-piezas musicales) como por comportamientos (prácticas habituales y estables del hacer música). Esos comportamientos van definiendo ex-crituras y preexcrituras corpóreas de las comunidades y de los individuos que las conforman, en una suerte de sustrato común, cuerpo social experencial y, por último, mente social.

De ese modo es posible hipotizar una empatía (Einfühlung) que se produce entre el músico (fuente-sonora) y su auditor: Músico-fuente (gesto sonoro) que, sin embargo, es definitivamente "cosa" y "cuerpo otro" para el auditor.

En la neurociencia existe el concepto de neurona-espejo cuya función es la de "hacernos sentir, querer y actuar con el Otro"15. Esa empatía está en la base de la afectación que surge entre músicos y auditores: la creación de un lugar común del emocionar que depende de las acciones y signos que anclan y constituyen ese emocionar como fenómenos estéticos. Es así como el gesto sonoro/cuerpo excrito del intérprete pasa a ser el espacio empático del auditor, que reproduce en su afectividad corporeizada dicha imagen y constituye la común-unidad, lugar del emocionar de ambos.

La referencia a imágenes o estados emocionales ha sido tratada en la crítica musical y la musicología desde muchos puntos de vista, pero siempre después de la mediación de signos definidos en base a palabras, como fruto de una actividad sugerida por la estructuración mental de los gestos sonoros y no como una directa presencia del cuerpo ex-crito de intérpretes y auditores, en una empatización prerracional. Es así que la distancia que los creadores "académicos" del siglo XX

\footnotetext{
${ }^{15}$ Lohmar 2005: 163-165.
} 
asuman respecto de las llamadas músicas programática se constituye en el rechazo a esta referencialidad reflexiva de la música, a esta imaginería musical, tan propia de cierta literatura decadente del romanticismo. La crítica especializada, bajo la influencia de la concepción hegeliana de la "razón de la historia", ha menospreciado esa posibilidad imaginífica del gesto sonoro como cuerpo-vivido-sonoro. De allí la conocida hipótesis adorniana que, postulando la audición estructurada como base de la experiencia musical, tendiente a articular estas células en series lingüísticas, ponía al centro de la apreciación estética de la música la capacidad de decodificar predicaciones y estructuras racionales como fuentes del placer musical y descartaba el gesto sonoro como directa expresión del emocionar.

Sin embargo, si deseamos rescatar al cuerpo vivido como espacio del emocionar, en ese fluir desde la cosa-mundo al ser-cuerpo, como movimiento en la doble hoja del adentro-afuera, la música aparecerá como ese doble movimiento que, a la vez que nos permite identificarnos personalmente, nos liga en una común-unidad afectivo-cultural. Ello nace desde la naturaleza misma de la práctica musical, desde sus fuentes sonoras originarias, gestos instrumentales y voz, que ex-criben el cuerpo vivido de intérpretes y auditores, como una resonancia, una atmósfera de contornos indefinidos, como el espacio del común emocionar.

\title{
BIBLIOGRAFÍA
}

\author{
Baricco, Alessandro \\ 2000 El alma de Hegel y las vacas de Wisconsin. Madrid: Editorial. Siruela, \\ Bateson, Gregory \\ 1984 Verso una ecologia della mente. Milán: Editorial Adelphin. \\ Damasio, Antonio \\ 2000 Sentir lo que sucede, cuerpo y emoción en la fábrica de la Conciencia. Santiago: Editorial \\ Andrés Bello.
}

Frazer, JAMES G.

1973 Il ramo d'oro. Turín: Editorial Boringhieri.

Hatten, Robert S.

2004 Interpreting Musical Gestures, Topics, and Tropes: Mozart, Beethoven, Schubert. Bloomington: Indiana University Press.

LOHMAR, DiETER

2005 "On the Function of Weak Phantasmata in Perception: Phenomenological, Psychological and Neurological Clues for the Trascendental Function of Imagination in Perception", Phenomenology and Cognitive Sciences, N 4, pp. 155-67.

Maurice Merleau-Ponty

1957 Fenomenología de la Percepción. México-Buenos Aires: Editorial Fondo de Cultura.

1995 La Nature, Notes. Cours du College de France. París: Editorial de Seuil.

NANCY, JEAN LUC

2002 A l'écoute. París: Ed. Galilee.

2003 Corpus. Madrid: Editorial Arena Libros. 
ROMERO, JUDITH

2006 "La fenomenología de Merleau-Ponty", en: http://concienciamusical.blogspot. com/2007/01/fenomenologia-de-la-percepcion-m.html obtenida el 18 Ene 2007 07:45:25 GMT.

Varela, Francisco; Thompson, Evan y Rosch, Eleanor

2005 De cuerpo presente, las ciencias cognitivas y la experiencia humana. Barcelona: Editorial Gedisa. 